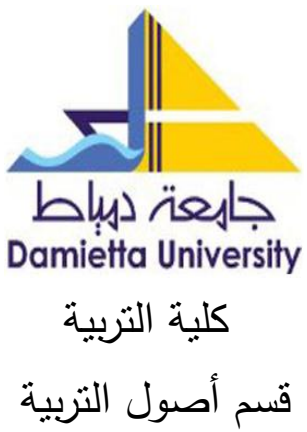

\title{
بمث بعنوان
}

\section{إدارة المعرفة مدفل لتمقيق الميرة التنافسية للتعهيم الثانوي العام بمصر}

\section{إعداد}

آمال عوض الاهشان

معلم خبير بإدرة التخطيط والمتابعة

بمديرية التربية والتعليم بدمياط
وائل وفيق رضوان

أستاذ أصول التربية المساعد

كلية التربية- جامعة دمياط

$$
r \cdot r \cdot|>| \leq \leq r
$$


مقدمة:

ازدادت أهمية المعرفة بأبعادها المختلفة في المؤسسات مع بداية التسعينات من

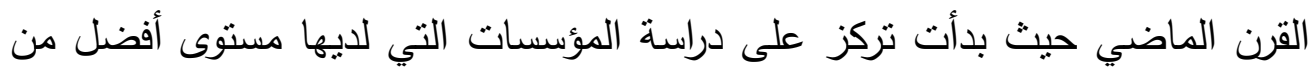
المعرفة أي تلك التي تتمتع بمستوى متميز في مجال كيفية الحصول على المعرفة والتعامل معها وتطبيقها والاستقادة منها ونتيجة ذلك ظهر مفهوم جديد أُطلق عليه: إدارة المعرفة فالمؤسسات التي حققت النجاح في الميادين التتافسية ليس أمادها إلا التفكير في إيجاد آليات تتمكن من خلالها ليس فقط تحقيق الميزة التتافسية بل تتعدى ذلك إلى السعي لاستدامتها، ويتم ذلك من خلال تبني استراتيجيات ملائمة تمكنها من الوصول إلى تحقيق الميزة التتافية على الأمد الطويل في ظل إدارة المعرفة. ويُعد الانفجار المعرفي من أهم القضايا التي تشغل دول العالم، حيث أصبئ أصبحت

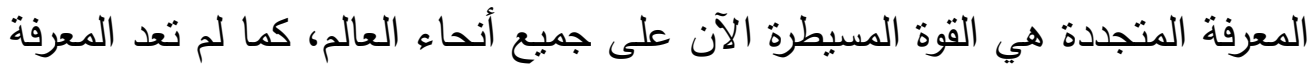
ثابتة أو محددة بنقطة بداية ونهاية، بل أصبحت متغيرة ولا نهائية، وقد أدى تعدد مصادر المعرفة وازدياد القنوات إلى تواصل الأفراد مع المراكز البحثية بسهولة بلة

(1) (1) ميسر

حيثُ أصبحت إدارة المعرفة في ظل هذه التغيرات والتطورات أفضل المداخل لتحقيق ذللك فهي لم تعد علمًا نظريًا يقوم على استقطاب المعلومات والمعارف وتقديمها مجردة وغير مقننة فحسب، وإنما تقوم على إيجاد بيئة مثيرة في المؤسسة تسهل عملية إبداع ونقل ومشاركة المعرفة من خلال التركيز على ثقافة المؤسسة فهي فلسفة ونهج وممارسة تعمل على تحقيق أهداف المؤسسة بالإضافة إلى أنها تخطيط وتتظيم ورقابة وتتسيق وتوليف المعرفة المرتبطة برأس المال الفكري لتحسين الحالة التتافية بدعم من بالإهي

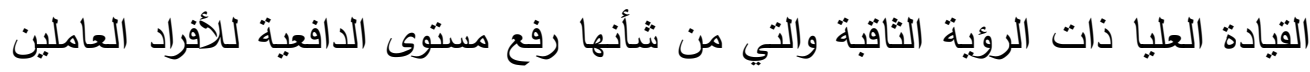
في المؤسسات، وكذلك تمكينهر من النطور والنمو المهني بأسرع وقت وبأفضل

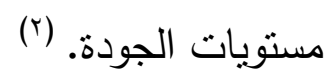

فإذا كان نقص المعرفة يُولد الخوف، فإن البحث عنها يُولا الثجاعة، ولذا، فمطلوب من المؤسسات التعليمية- خاصة مدارس التعليم الثانوي العام- ليس فقط ئط 
الارتقاء بالمعرفة، بل الإبحار فيها وتشكيلها، لنتواكب مع هدف التربية للألفية الثالثة لتوفظ المكنون الفكري داخليًا، وخلق ظروف وإمكانات جديدة نحو اكتشاف المجهول

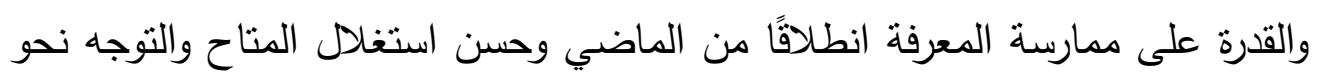
المستقبل. فلا قيمة للمعرفة إن لم تمارس في مناحي الحياة لتعطي قيمة مضافة للقوة

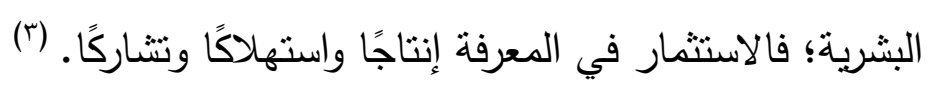
مشكلة اللدراسة:

من البديهي أن تَّدم الثعوب يُقاس بمدى اهتمامها بالتربية والتعليم؛ لأن

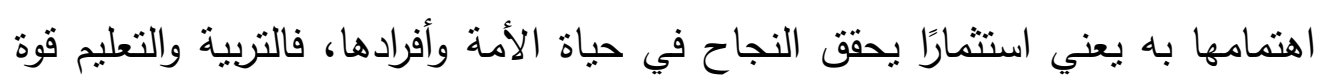
مؤثرة وفاعلة بما تساهم به في تثقيف الأفراد وتتويرهم.

وعلى الرغم من الجهود الكثيرة التي تهدف إلى تطوير العملية التعليمية بمؤسسات التعليم الثانوي العام لتحسين جودة مخرجاته، وهذا ما هدفت إليه دراسة حسين والرشيد (9 ( ب) ()) في التعرف على تصورات القادة التربويين لمنطلبات تطبيق إدارة المعرفة في المدارس الثانوية. وتعظيم قدراتها التتافية وهو ما أكدت عليه دراسة

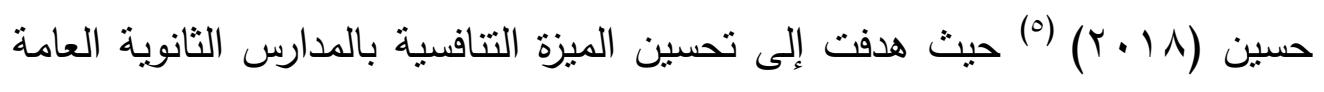
في ضوء مدخل رأس المال الفكري، وبناء تصور مقترح يمكن تطبيقه بالمدارس الثانوية العامة. إلا أن التقام في هذا المجال لم يزل بطيئا، في ظل محاولة لتحقيق جودة

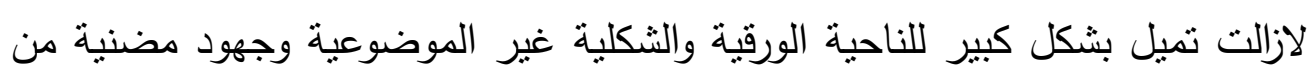
العاملين بالمدارس تستتفذ معظم أوقاتهم بصورة تبعدهم عن عملهم الحقيقي كمعلمين.

اعتماداً على ما سبق يمكن صياغة مشكلة الدراسة في التساؤل الرئيس التالي: كيف تكون إدارة المعرفة مدخلاً لتحقيق الميزة التتافسية للتعليم الثانوي العام بمصر؟ ويتقرع من هذا التساؤل عدة أسئلة فرعية على النحو التالي: - ما - ما الإطار النظري والمفاهيمي لإدارة المعرفة؟ - ما - مالإطار النظري والمفاهيمي للميزة النتافسية؟ - ما أبرز ملامح التعليم الثانوي العام في مصر؟ 
- ما أهم المشكلات التي تواجه التعليم الثانوي العام في مصر؟

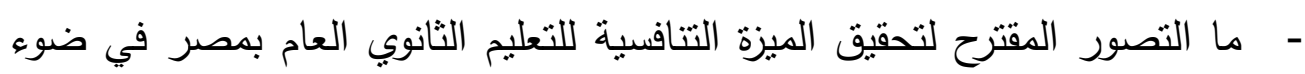
إدارة المعرفة؟ - من

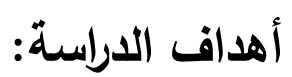

تههف الدراسة الحالية إلى التعرف على الإطار النظري والمفاهيمي لإدارة

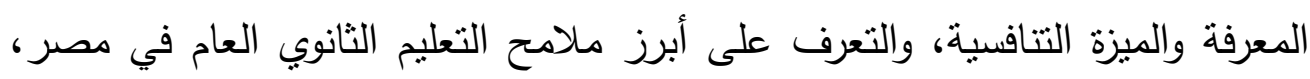
وأهم المشكلات التي تواجهه، مع وضع تصور مقترح لتحقيق الميزة التتافسية للتعليم الثانوي العام بمصر في ضوء إدارة المعرفة.

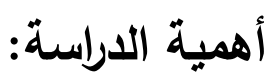

تكمن أهمية الدراسة الحالية في أهمية متغيراتها حيثُ تُعد من الموضوعات المهمة في ميدان الادارة، إذ تتتاول مفهومين مهمين هما: إدارة المعرفة، والميزة

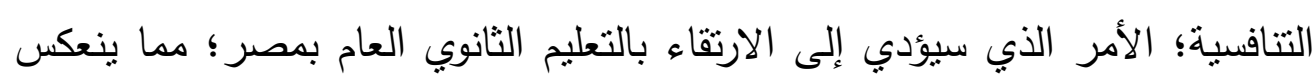
على رفع كفاءة العملية التعليمية ككل.

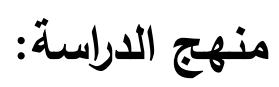
تعتمد الدراسة على المنهج الوصفي الذي ينتاول الواقع ومشكلاته تحليلاً ناقداً

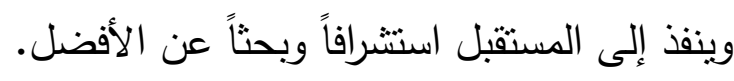
مصطلحات الاراسة:

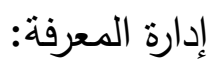
هي عملية تحليل وتركيب وتقييم وتتفيذ التغيرات المتعلقة بالمعرفة لتحقيق الأهداف الموضوعة بشكل نظمي مقصود وهادف من أجل إيجاد قيمة للأعمال وتوليد الميزة التنافسية. (v) وتُعرف إدارة المعرفة إجرائيًا بأنها: العمليات المعرفية التي تساعد المدرسة على توليد

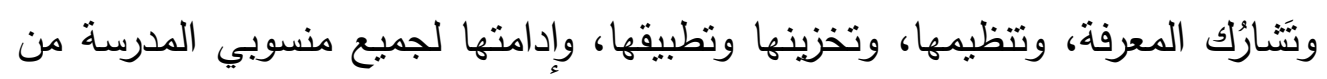


معلمين وطلاب وعاملين ومستقيدين، والتي تتمتل في المجالات الآتية: مجال متطلبات (الثقافة التنظيمية، الهيكل التنظيمي، القيادة والإدارة، تكنولوجيا المعلومات). الميزة التنافسية: تعني مجموعة من العوامل التي تساعد المؤسسة على التتافسية، منل: الموارد والأصول والمهارات التي يمكن التحكم فيها والسيطرة عليها وتتسيقها واستتمارها بما يحقق منفعة وقيمة أفضل للعميل أو المستهلك، وتحقق تميزًا وتفوقًا على بقية المنافسين، وتسمح

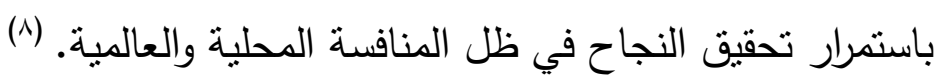
وتُعرف الميزة التتافية إجرائيًا بأنها: مجال تتمتع فيه المؤسسات التعليمية بقدرة أعلى من منافسيها في استغلال الفرص الخارجية أو الحد من أثز التهديدات، بحيث تسنطيع المؤسسة التعليمية أن تميز نفسها عن أقرانها ومنافسيها وتحقق لنفسها التفوق والتميز .

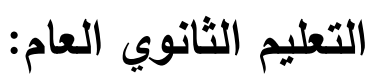
حدده القانون (9 1) لسنة (919 1 بأنه المرحلة التي تعقب مرحلة التعليم الأساسي،

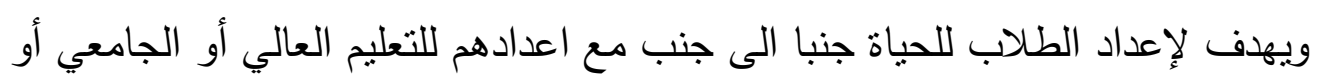

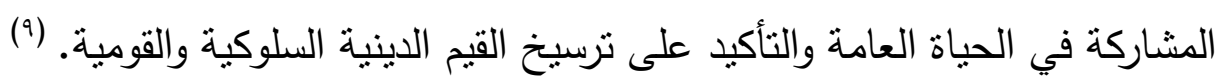

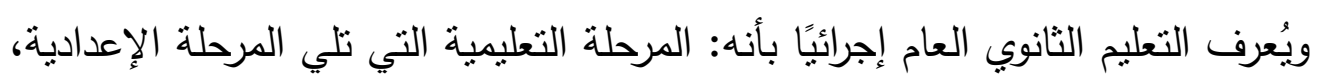

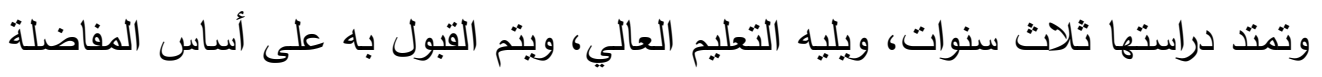
بين المنقدمين في مجموع درجاتهم في شهادة نجاح إتمام الدراسة بمرحلة التعليم الأساسي. الأدب النظري

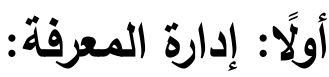

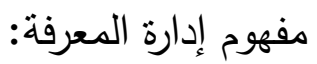
تعددت المفاهيم المقدمة للمعرفة بتعدد وجهات نظر الباحثين والكُتاب في هذا الثأن، فهناك من ينظر إليها على أساس أنها معلومات أو عناصر يمكن تخزينها ومعالجتها، وأخر ينظر إليها على أساس أنها خبرات منراكمة سواء في رؤوس الأفراد 
أو في الذاكرة التنظيمية للمؤسسة، ووهناك من ينظر إليها على أساس أنها نوع من

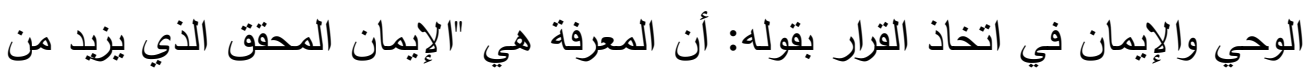

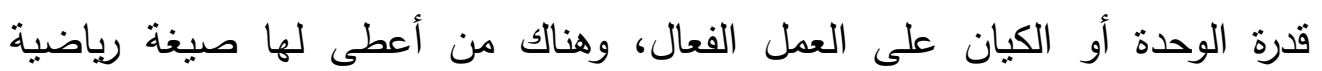

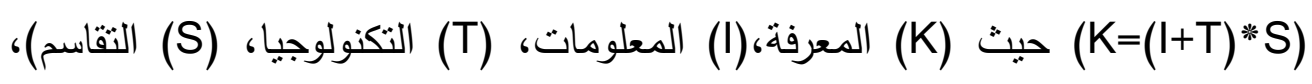

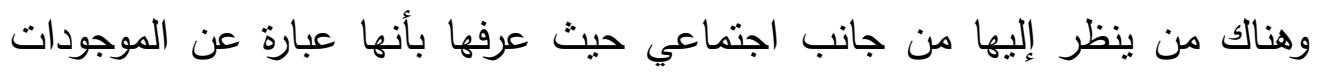

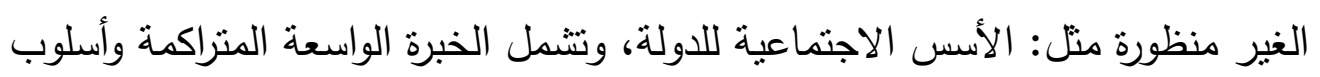

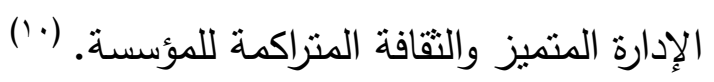

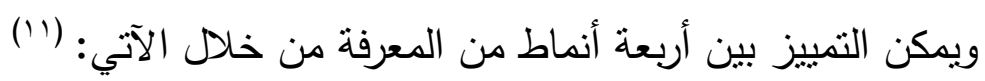

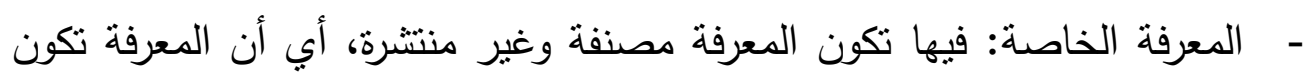

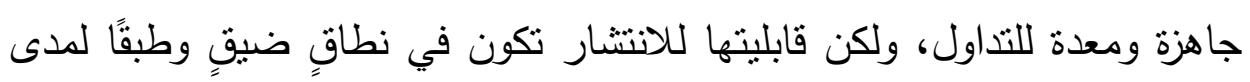
الحاجة اليها في إطار سياسات المؤسسة. - المعرفة الثخصية: حيث المعرفة تكون غير مصنفة وغير منتنرة أيضًا متلك:

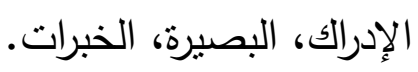
- المعرفة العامة: وتكون المعرفة مصنفة ومنتشرة مثل: الصحف، الكتب، المكتبات.

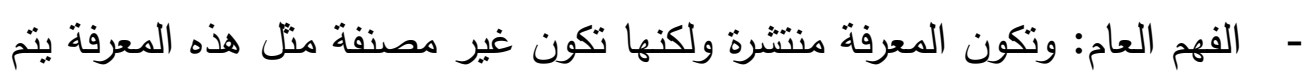
تكوينها ببطء من خلام عملية التنشئة والتواصل الاجتماعي.

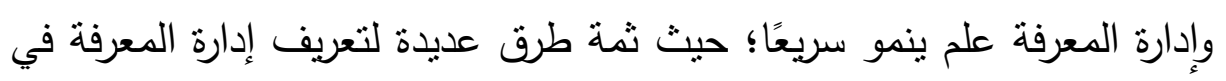

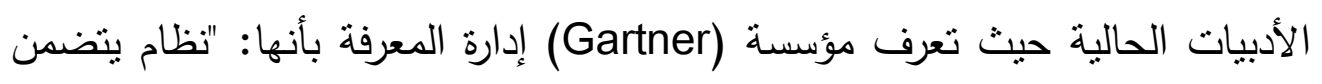

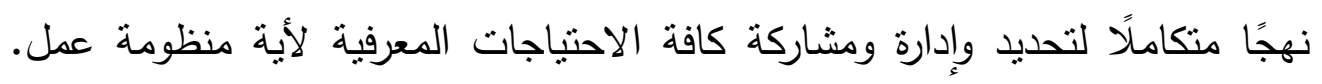

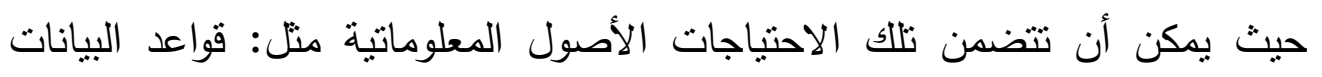

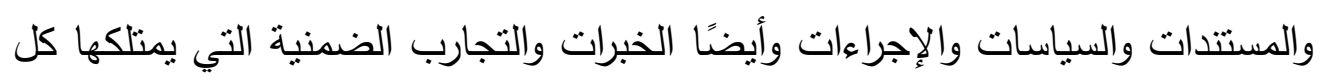

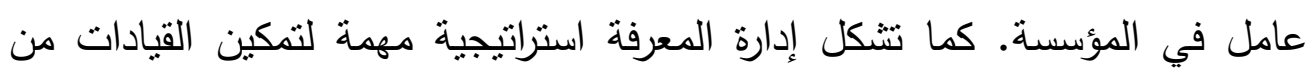

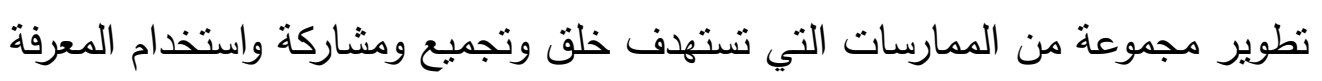

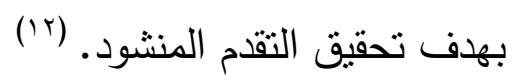


وتُعَرف إدارة المعرفة بأنها مجموعة من العمليات والأنشطة التي تتحكم بالمعرفة من خلال توليدها ونشرها واستخدامها عن طريق استغلال المهارات والخبرات لدى بات الأفراد والعاملين في المدرسة والتي تعتبر ضرورية للأنشطة الإدارية كاتخاذ القرارات وحل المشكلات. (r) - (ir)

وتشترك المؤسسة المُتعلمة مع عمليات إدارة المعرفة، فهي تقوم باستقطاب

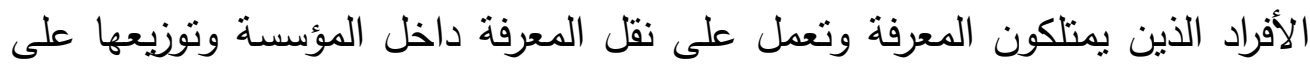
العاملين، ثم يتم تحويلها إلى ممارسات فعالة في المؤسسة وتحقيق التوافق الاجتماعي

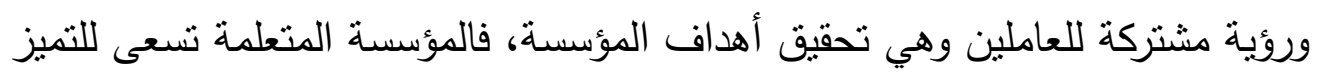
من خلا تحقيق التكيف مع المستجدات الخارجية والامكانات المنواجدة، كما تتمتع المؤسسة المتعلمة بييئة خصبة تسهم بتحريك جميع الاتجاهات بالمؤسسة، ولا تقتصر

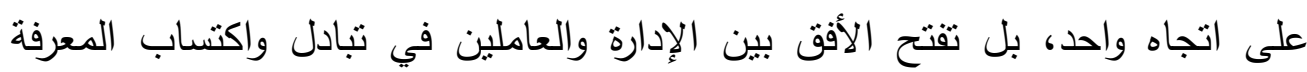
ونشرها وفي حل الصعوبات التي تعترض المؤسسة أي تسمح بأخذ المشورة والحلول من المستويات الأخرى العاملة بالمؤسسة، ويسهم العاملين في وضع الاستراتيجية التي

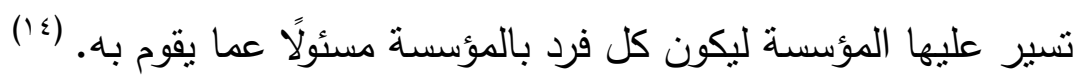

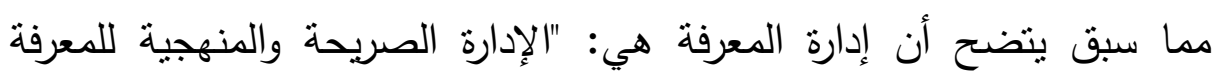
الحيوية وما برتبط بها من عمليات إنشاء أو جمع وتتظيم ونشر واستخدام واستغلال سعيًا لتحقيق الأهداف التتظيمية". (10) أهداف إدارة المعرفة:

تهدف إدارة المعرفة إلى تحقيق الآتي: (ז') - أسر المعرفة من مصادرها وخزنها وإعادة استعمالها. - جذب رأس مال فكري أكبر لوضع الحلول للمشكلات التي تواجه المؤسسة. - خلق البيئة التظيمية التي تشجع كل فرد في المؤسسة على المشاركة بالمعرفة لرفع مستوى معرفة الآخرين. تحديد المعرفة الجوهرية وكيفية الحصول عليها وحمايتها. - - إعادة استخدام المعرفة وتعظيمها. 
- بناء إمكانات التعلم وإنشاعة ثقافة المعرفة والتحفيز لتطويرها والتتافس من خلال الذكاء البشري.

- التأكد من فاعلية المؤسسة ومن تحويل المعرفة الضمنية إلى معرفة ظاهرة وتعظيم العوائد من الملكية الفكرية عبر استخدام الاختراعات والمعرفة التي بحوزتها والمتاجرة بالابتكارات. - تحول المؤسسات من الاقتصاد التقليدي إلى الاقتصاد العالمي الجديد (اقتصاد المعرفة) وتعمل كثبكة للأنشطة، حيث تسهم في التحول نحو الثبكات الاقتصادية الواسعة والتجارة الإلكترونية. - تعمل على جمع الأفكار الذكية، وتسهم في نشر أفضل الممارسات في الداخل. - تهدف إلى الإبداع والوعي والتصميم الهادف والتكيف للاضطراب والتعقيد البيئي والتظيم الذاتي والذكاء والتعلم. - خلق القيمة للأعمال من خلال التخطيط لها وجودة العمليات وإدارة وتطوير العاملين وإدارة الزبائن وتقييم الإنتاج.

عمليات إدارة المعرفة:

هي أحد عناصر إدارة المعرفة، في أربعة أبعاد يتم تقسيمها كالتالي: ('v) 1ـ توليد المعرفة: وتُعد من أهم عمليات ادارة المعرفة، والتي تتضمن ابتكار واكتساب وشراء المعرفة، ذو القدرة على الفهم والاستيعاب للمعرفة الظاهرة، والحصول على المعرفة الكامنة في أذهان وعقول المبدعين، ويجب أن يفهم ان ذلك لا يعني الحصول على معرفة جديدة فحسب وإنما القدرة على الإبداع وتطوير الأفكار والحلول كقيم مضافة، مع الأخذ في الاعتبار ضرورة المزج بين المعرفة الصريحة والضمنية الكامنة لتكوين معان ومعارف جديدة من هذا المزيج. ץ-خزن وتنظيم واسترجاع المعرفة: وتتشمل العمليات التي يتم من خلالها الاحتفاظ بالمعرفة والمحافظة عليها وإدامتها وتتظيمها وتسهيل البحث والوصول إليها وتيسير سُبل استرجاعها ويكون لاستخدام تقنيات المعلومات دورٌ بارز في جميع مراحل هذه 
العملية وتُعد هذه العملية بمثابة الذاكرة التظظيمية للمؤسسة التي تشتمل على المعرفة الموجودة في أنشكال مختلفة بما فيها الوثائق المكتوبة والعمليات المخزنة في قواعد البيانات الإلكترونية، والمعرفة الإنسانية المُخزنة في النظم الخبيرة. والمعرفة الموجودة في الإجراءات والعمليات التتظيمية الموتقة. والمعرفة الضمنية المكتسبة من الأفراد. وتكتسب هذه العملية أهميةً كبرى في المؤسسات التي تعاني من معدلات عالية لدوران العمل التي لا يوجد لدى موظفيها استقرارًا بسبب صيخ التوظيف المؤقتة عبر العقود القصيرة الأجل والتي قد يغادرونها وبالتالي فقدان المعرفة الضمنية التي يحملها هؤلاء الأفراد بسبب عدم توثيقها. r-نقل ومشاركة المعرفة: وتعني نشر ومشاركة المعرفة بين مختلف الأفراد في المستويات الإدارية المختلفة، حيث يستغل الأفراد مهاراتهم في ذلك ويتم توزيع المعرفة الضمنية بأساليب مختلفة كالتدريب والحوار، أما المعرفة الصريحة فيمكن نشرها بالوثائق والنشرات الداخلية والتعلم. ويكون للدعم الإداري دور مهم في ذلك ويكون للتكنولوجيا المتوفرة أيضًا دور في تسهيل توزيع والتتارك بالمعرفة عبر شبكة الاتصال الاخلية والبريد الإلكتروني. ونُظم الأرشفة والإدارة الإلكترونية. والمهم في عملية التوزيع، هو ضمان وصول المعرفة الملائمة إلى الثخص الإنده الباحث الإنه عنها في الوقته الملائم.

ع- تطبيق المعرفة: وهي العملية المرتبطة بتطبيق المعرفة والتي يجب أن تأخذ حقها من الاهنمام فالمعرفة تكتسب بالعمل وتتطلب كثيرًا من التعليم الذي يأتي عن طريق الممارسة والتجريب والتطبيق. وهنا لابد من إيجاد الثقافة التتظيمية التي تساعد في ذلك كالتشجيع والتسامح والتعليم من الأخطار ، كما أن الإدارة الناجحة للمعرفة هي التي تهنت

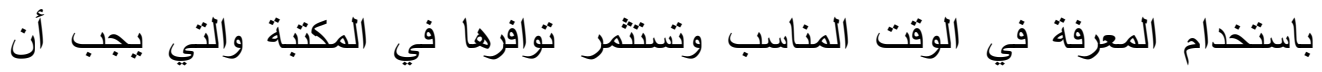
تُوظَفَ في حل المشكلات التي تواجهها وكذا في المساعدة في تحقيق أهدافها وعليه فإن أي مؤسسة تسعى إلى تطبيق جيد للمعرفة هي التي تهنم بتعيين مدير لإدارة

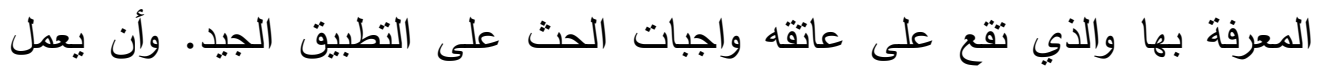
كعنصر يهنم بتكريس أولوية لنطبيقات المعرفة، ويسعى في فتح قنوات الاتصال 
الرسمية وغير الرسمية ويسعى للحصول على التقارير، والموضوعات ذات العلاقة. ويهتم بجلسات التدريب وتتجيع فرق العمل الجماعية، ويستخدم التكنولوجيا لتمكين فرص أكبر لتوليد المعرفة.

\section{معوقات تطبيق إدارة المعرفة:}

يُمكن تلخيص المعوقات التي تواجه تطبيق إدارة المعرفة بالآتي: (^’') - - ضعف البنية التحتية المطلوبة لإدارة المعرفة، أو ضعف استخدامها بالآلية المناسبة. - الاعتقاد بأن الوصول إلى المعرفة وتدوينها هو الهدف، وليس استخدامها وتطبيقها.

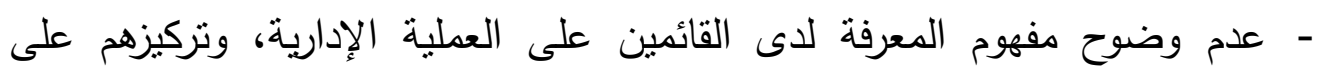
المعرفة الصريحة دون البحث عن المعرفة الضمنية، والتي تكون في معظم الأوقات

$$
\text { هي الأهم والأكثر فاعلية. }
$$

- عدم وجود الدعم من الإدارة العليا والافتقار للكوادر البشرية. - ضعف الموارد المالية والمادية اللازمة لنجاح العملية الإدارية.

- الروتين والسلبية في أداء العمل ما ينعكس على ضعف القيام بالمهام، وظهور روح اللامبالاة والابتعاد عن الابتكار ، والتجديد وكل ذلك ينعكس سلبًا على تشكيل معرفة برة

جديدة، بل على العكس ما يؤدي إلى ترهل المعرفة الحالية واضمحلالها.

ثانيًا: الميزة التنافسية:

أرغمت المنافسة العالمية الدول والمؤسسات العامة والخاصة إلى الاهنمام

بتحقيق تتافسية لها، وإعادة التفكير في استراتيجياتها، وكيفية استثمارها لمواردها المختلفة من أجل تحقيق أهدافها بجودة وتميز؛ لذلك فقد ظهر مفهوم التتافسية وحظى تلى باهتمام الباحثين في الخمسينات وبداية الستينات من القرن العشرين في دول أوروبا

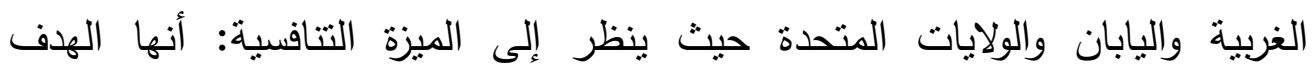
(الغرض) العام لاستراتيجية العمل. حيث ثُمثل الميزة التتافسية القاعدة الأساسية التي يرتكز عليها أداء المؤسسات، ومن النادر أن تمنلك تلك المؤسسات سبقًا تتافيًا على كافة الأصعدة وفي جميع المجالات قياسًا للمنافسين الآخرين، ونظرًا لمحدودية موارد المؤسسة من جانب، وعمل 
قرارات منبادلة لغرض بناء قدرات مميزة تستند وتتبادل التأثنر مع الإدارات المميزة للمؤسسة من جانب آخر ؛ وهكذا فالميزة التتافسية تُعد مفتاحًا لنجاح تلك المؤسسات. (19) تعريف الميزة التنافسية:

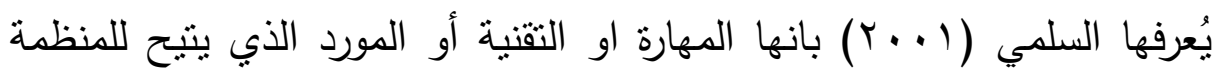

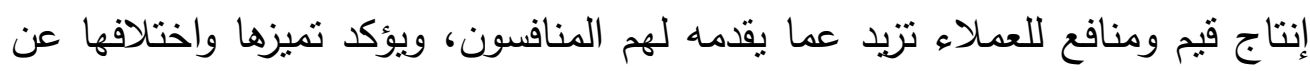
هؤلاء المنافسين من وجهة نظر العملاء الذين يتقبلون هذا الاختلاف والتميز ، حيث يحقق لهم المزيد من المنافع والقيم التي تتفوق على ما يقدمه لهم المنافسون

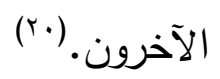

كما تُشير إلى قدرة المنظمة على صياغة وتطبيق الاستراتيجيات التى تجعلها في مركز أفضل بالنسبة للمنظمات الأخرى العاملة في نفس النشاط وتتحقق من خلال الاستغلال الأفضل للإمكانيات الفنية والمادية والمالية والتنظيمية بالإضافة إلى القدرات

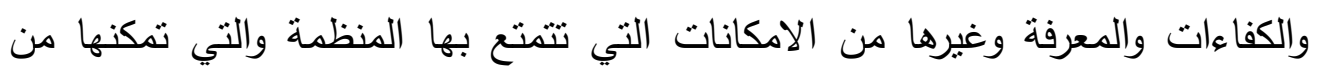
تصميم وتطبيق استراتيجيتها التنافسية ويرتبط تحقيق الميزة التتافسية ببعدين أساسيين

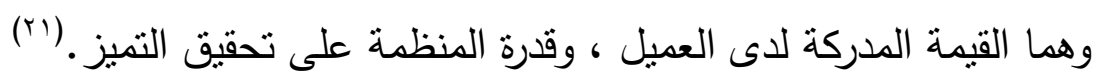

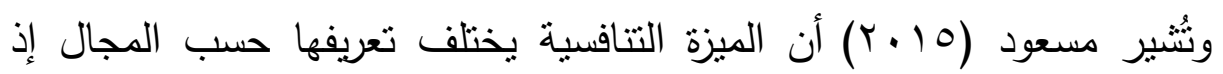

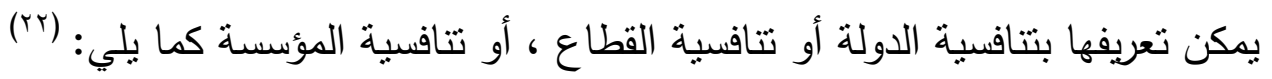

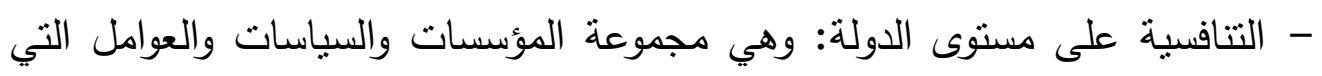
تهدف إلى تحديد مستوى الإتتاجية لبلد ما، ومن ثَم تحديد مستوى مستدام من الازدهار والاستقرار الاقتصادي مع تحقيق مستويات مرتفعة من الدخل للمواطنين.

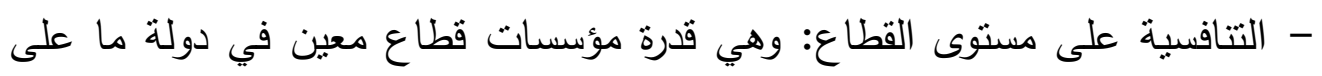

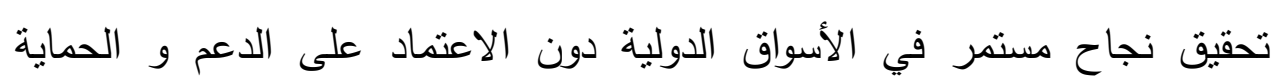
الحكومية. - التتافسية على مستوى المؤسسة: وهي قدرة المؤسسة على تصميم وإنتاج وتسويق منتجات متقرقة مقارنة بما يقدمها منافسوها، حيث يرجع ذللك التفوق إلى عدة عوامل منل : السعر والجودة والتقدم التقنى وغيرها. 


\section{مصادر الميزة التنافسية:}

تتمثل أهم مصادر الميزة التتافسية في الآتي: (rr) - التكنولوجيا والابتكار من أجل ميزة تنافسية: فصططلح الابتكار له جانب تجاري الهي

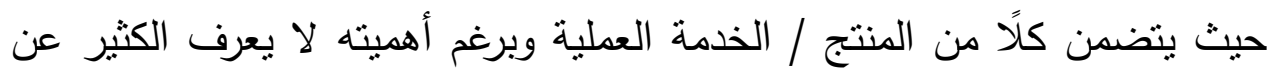
كيفية تحرك الابتكار التكنولوجي في المؤسسات المختلفة فالمؤسسات الأكثر ابتكارًا تتارك في بحث مستمر عن أفضل المنتجات والخدمات ويحاولون باستمرار ترقية قدراتهم الداخلية وغيرها من الموارد فالابتكار يُعزز الإنتاجية ويعمل على زيادة كفاءة الدولة لمواردها. - الموارد البشرية لميزة تنافسية: فالموارد البشرية مصطلح يُستخدم لوصف الأفراد الذين يشكلون القوى العاملة في المؤسسة فالمصادرة التقليدية للميزة التتافسية منل الموارد المالية والطبيعية والتكنولوجية. هي أقل أهمية للميزة التنافسية خاصة في المقارنة إلى هيكل اجتماعي معقد منل نظام التوظيف إذن فسياسات وممارسات الموارد البشرية قد يكون مصدرًا مهما للميزة التتافسية المستدامة. - الهيكل التنظيمي للميزة التنافسية: المؤسسة هي البديل عن الكيانات المجمعة ويمكن هيكلة المؤسسة بعدة طرق مختلفة اعتمادًا على أهدافهم ستحدد بنية المؤسسة البسة فالأساليب التي تعمل بها ومدى تخصيص المسئوليات لمختلف المهام فالضغوط التنافسية المتزايدة تجبر المؤسسات على التركيز على كفاءاتها الأساسية وإعادة رسمها حدودها فتغير الهياكل التنظيمية إلى متعددة الأقسام من خلال تحويل

$$
\begin{aligned}
& \text { الأعمال نحو وحدات أصغر لامركزية. } \\
& \text { أهمية الميزة التنافسية: }
\end{aligned}
$$

تمثل البيئة التتافسية القاعدة الأساسية التي يرتكز عليها أداء المؤسسات، ولا

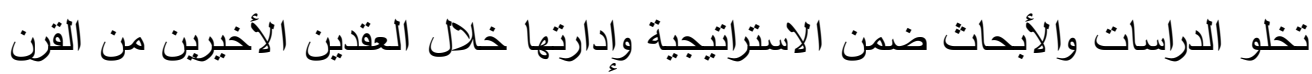

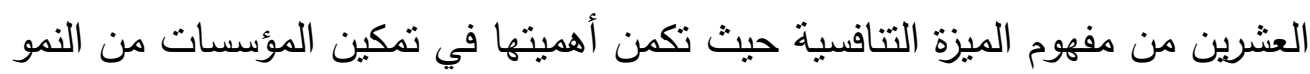

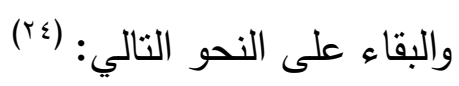
- تُساهم في إيجاد التحسينات المستقبلية للمؤسسة. 
- تقديم التوجيه والتحفيز لجميع العاملين في المؤسسة. - ت تساعد على توليد سمعة أو شهرة للمؤسسة في أذهان العاملين. - - توفر نظامًا يمتلك ميزة فريدة تتفوق بها المؤسسة على المؤسسات المنافسة لها. - تتحقق للمؤسسة قيمة مضافة إلى منتجاتها بما يساعد على جذب العملاء. - تلبي احتياجات وتوقعات العملاء بالحصول على خدمة أو منتج ذي جودة عالية. - - تخفيض الكلفة وتحقيق الجودة العالية. - تُعطي المؤسسة تقوقًا نوعيًا وكميًا وأفضلية على المنافسين، وتتيح نتائج أداء عالية.

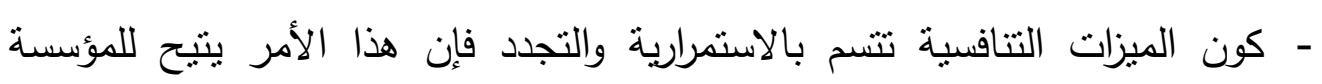
متابعة التطور والتقدم على المدى البعيد.

استراتيجيات الميزة التتافسية: (Competitive advantage strategies)

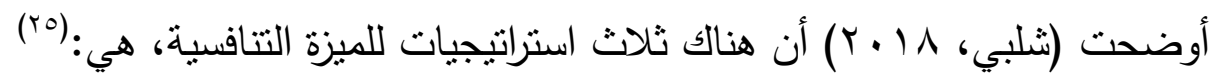

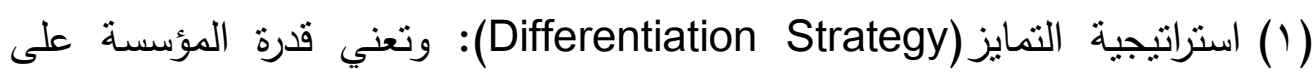
تقديم منتجًا مميزًا وفريدًا وخدمات على مستوى عالٍ من الأداء والتطور .

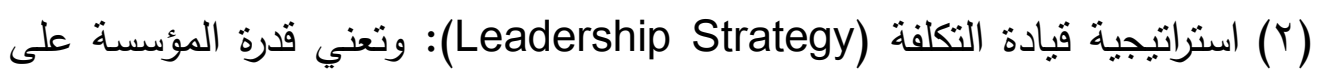
تصميم وتصنيع وتسويق منتج أقل تكلفة بالمقارنة مع المؤسسات المنافسة، وبالتالي تحقق عائد أكبر مع الحفاظ على مستوى عالٍ من الجودة. (r) استراتيجية التركيز (Strategy Focus): من خلال توجيه جهود المؤسسة لتكون أكثر كفاءة لخدمة قطاع معين من العملاء وتحديد أهداف معينة للتركيز عليها وتحقيق الريادة فيها، وهي تختص بتقديم مزيج سلعي ضيق من حيث الاتساع

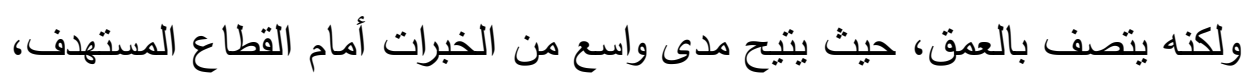
والاعتماد على الفهم الدقيق لحاجات وخصائص المستهلكين.

فالميزة التتافسية تذور حول أربع محددات رئيسة (4CS)، وهي: (بr) ا- الإبداع والابتكار: وهو يمثل الدافع الأساسي الذي يحدد ويحافظ على حركة

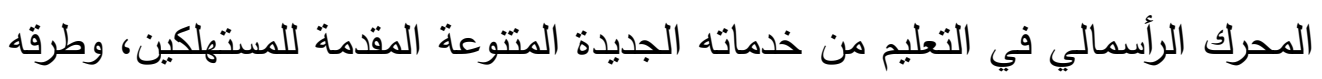
الجديدة كذلك للإنتاج والنقل، وأسواقه الجديدة بالإضافة إلى الأثكال الجديدة من تتظيم 
صناعته حيث يمكن للمؤسسات الحصول على ميزة تتافسية من خلال مبادرات إدارية تُشهل الابتكار، الكفاءة، التعلم؛ لتبرز أفضل ما في الناس من أداء في الفوز بثقافة منئ موجهة. r- التنافس: فالمنافسة هي الفعل والاستجابة أو الاستباق والهجوم في اشتبالك تتافسي قائم ضد الخصوم وغالبًا ما تكون الميزة النتافسية التي تم اكتسابها من خلال مناورات تتافسية في كثير من الأحيان مبنية على الملكية (Owner ship- Based) كالموقف القوى في السوق أو على الوصول (Access-Based) كالفوز على المنافسين من خلال تأمين قناة التوزيع السائدة في الأسواق الخارجية المتنازع عليها بشكل عام مشترك. r- التعاون: وهو المبادرة بالتزتيبات التعاونية والمشاركة فيها مع آخرين في البيئة المحيطة بمؤسسة التعليم، ويهدف إلى تحقيق الفائدة العظمى من خلال العمل المشترك. ع - الاستمالة: وهي أن تتخرط مؤسسات التعليم في مناورات استراتيجية تعرف باسم الاستمالة، والتي تساعد في الحصول على دعم من الجهات الحكومية أو أصحاب المصلحة المحليين المؤثرين.

\section{ثالثًا: التعليم الثانوي العام في مصر:}

لم تَعَدُ أهمية التعليم (خاصة التعليم الثانوي العام) محل جدل في أبي بلدٍ في العالم؛ حيثُ أن بداية التقدم الحقيقية هي التعليم، ولا يستطيع أي مجتمع تحقيق أهداف التتمية الثاملة ومواجهة متطلبات المستقبل إلا بالمعرفة. فالتعليم المدرسي و (خاصة الثانوي العام)- على الصعيد العالمي بصفة عامة ومصر بصفة خاصة- يُمنل قضية أمن قومي؛ إذ يُمنل القاعدة التي ترتكز عليها مقومات

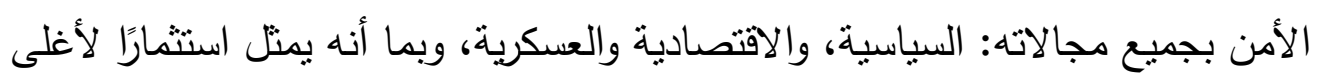
الثروات التي يملكها المجتمع وهي الثروة البشرية، فلا بد أن تجرى عليه عمليات تقييم ومراجعة وإصلاح ومتابعة عملية مستمرة لا سيما وأن الدراسات التي أُجريت على هذا لئه النظام، أشارت إلى وجود العديد من المشكلات الواجب الإسراع في حلها. (rV) 
وتُشير الإحصائيات إلى أن هناك تفاوثًا في الالتحاق بالتعليم الثانوي العام بين

الذكور والإناث في محافظات مصر المختلفة، وهو ما أكده تقرير تقييم المحافظات الذي أثنار إلى التقوق في تعليم الإناث على الذكور في تسعة عشرة محافظة من محافظات جمهورية مصر العربية بينها خمس محافظات نشهد تفوفًا كبيرًا للإناث هي: الإنات محافظات دمياط وأسوان والبحر الأحمر وبورسعيد والسويس، بينما كانت محافظات جنوب سيناء والجيزة وقنا وأسيوط والفيوم وبني سويف وسوهاج هي الأكثر تفوفًا بالنسبة

للأكور في التعليم الثانوي العام. (r^) فالتعليم يعتبر أداة صنع المستقبل وبوابة تحقيق الأمن المعرفي للأمم، ولكي ينجح في أداء رسالته المتمنلة في توفير رأس المال البشري القادر على إنتاج المعرفة وحول مشعل التتمية الإنسانية والمجتمعية المستدامة، لابد أن نستتد الأنظمة التعليمية إلى إلى سياسة مُستبصرة تدرك جيدًا متطلبات الحاضر وتسعى إلى تأمينها، دون أن يشغلها ذللك عن استشراف آفاق المستقبل والتهيؤ لها. (ra)

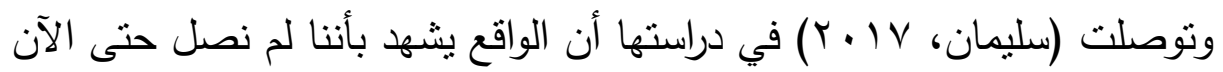
لمنتج تعليمي عالي الجودة فما زالت الثكوى مستمرة من ضعف الثقة لدى أولياء الأمور في إدارة المدارس وقدراتها، لاسيما الحكومية منها، وتوجيههم نحو المدارس كن الخاصة أو التجريبية على الأقل، واستمرار بعض الظواهر السلبية كظاهرة الغياب والعنف بين طلاب المرحلة الثانوية العامة وتفشي ظاهرة الدروس الخصوصية ونَبعت أهمية الاهتمام بمشكلات نظام الثانوية العامة من إدراك حقيقي لما يعانيه النظام من لفن

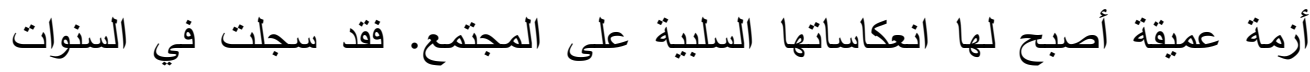
الأخيرة عددًا من الأبحاث والدراسات التي تتاولت مشاكل التعليم الثانوي العام، تؤكد أن أن أوضاعه في حاجة لمواجهة مشكلاته بشكل جذري. (r.") وفي دراسة (محمد، 9 ( ب ) رأت أن من الأسباب التي أودت بالتعليم الثانوي

العام إلى الضعف: (r) (r) (1) - عدم استقرار السياسات التعليمية وسرعة تغيرها من وزير إلى آخر بل احيانًا في

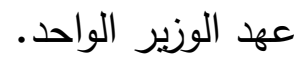


- لا يوجد خريج مبدع ومستمر فقد خلت العملية التعليمية من روح التفكير والابداع مع استمرار الفصل بين الجانب النظري والعملي بالإضافة لافتقاد الخريجين للمهارات التي يحتاجها سوق العمل. - سيادة القيم المادية على عقلية المواطن المصري التي دفعت الكثير من أولياء الأمور إلى الاعتقاد أن الهدف الرئيسي للتعليم هو حصول أبنائهم على مجموع يؤهلهم للالتحاق بنوع ومستوى التعليم الذي يفضلونه؛ مما ينعكس على نظرتهم الدونية للمدرسة.

- عدم اكتفاء المعلم اقتصاديًا وذللك لضعف رواتبهم وبالتالي جعل المهنة طاردة لهم. ولعل من أهم التطورات في المرحلة الثانوية استخدام أجهزة التابلت (الحاسب اللوحي) مُحَمل عليها المناهج وبنك المعرفة في التعليم، واستخدام بنك الاسئلة والامتحانات الإكترونية على مستوى كل مدرسة وليس على مستوى الجمهورية، وتصحيح الامتحانات بشكل إلكتروني، وتطبيق النظام التراكمي في التقويم على مدار

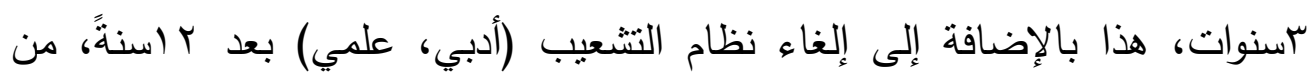
تخرج أول فوج من نظام الثانوية العامة الجديد. (r؟r) وفي سبيل ذللك فقد حدد (مظهر، V. . . r) مشروعًا لتدريب الطالب، وصقل مهاراته للتعامل مع المعلومات ثم تطوير معلوماته حتى تصبح معرفة ثم علمًا، وتدريب الطالب على ربط العلم بالعمل من خلال تطبيقه لأدوات المعرفة على مشاكله ليحلها ويتأكد من صلاحية الحل ثم يضع خطوات لتتفيذ الحل وهذه العناصر هي: (rr) المعلومات استقبالًا: حيث يجب تدريب الطالب على تمييز مصادر المعلومات وتصنيف أشكالها وتدريب الحواس على استقبالها وعلى استعمال الأجهزة التي تزيد قدراته لاستقبال المعلومات. المعلومات معالجةً: حيث تدريبه على وصف ما تستقبله حواسه وتصنيفها ثم التدرج به في مراحل الاستيعاب المختلفة من تكوين مدركات أولية بسيطة منفصلة ثم محاولة تجميع المفردات المعرفية إلى أفكار ثم نظريات والتدريب على التحقق من مصداقية النظريات البسيطة ثم مرحلة التذرب على التجريد والربط بين الأفكار والتصورات 
والنظريات الأكثر عمومية، وفيها يتم شحذ مهاراته الخاصة بالمعرفة منل: التحليل والتركيب والاستقراء والاسنتباط والاستتناج. المعلومات حفظًا وتخزينًا: حيث يُدرب الطالب على استخدام الذاكرة في الأوراق

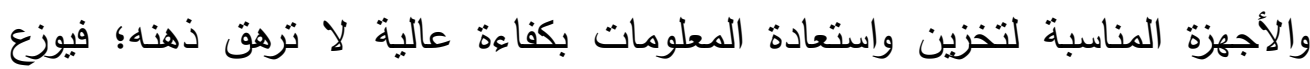
المعلومات المناسبة في المخازن المناسبة، فيستطيع أن يميز بين الخاص والعام، المقيد

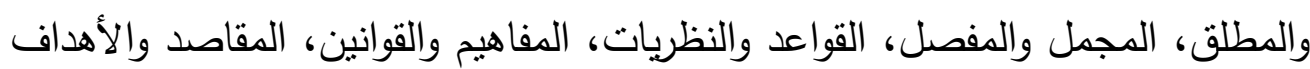
فيحفظ له الأولوية. المعلومات إرسالاً: يتدرب الطالب على الطرق المختلفة لتمثيل ونقل المعلومات عن طريق الرسم والحوار والنقاش والكتابة والخطابة أو الإشارة والحركة -نحن هنا في مجال حيوي للإنسان هو مجال الاتصال والتواصل. المطلومات استعمالًا: حيث يتدرب الطالب على استعمال المعلومات من حيث المحتوى ولتواهل والتوقيت، ومن حيث الإنجاز أو الإطناب وعن طريث استخدام الوسائل المناسبة من أجل أخذ قرار أو كسب موقف أو علاج مشكلة. رابعًا: التصور المقترح لتحقيق الميزة التنافسية للتعليم الثانوي العام بمصر في ضوء إدارة المعرفة: تواجه مبادرات إدارة المعرفة مثلها مثل مجالات الممارسات الأخرى - تحديات عديدة، وقد كثفت بعض الأرقام فنثل إدارة المعرفة وذللك يرجع إلى سببين رئيسين

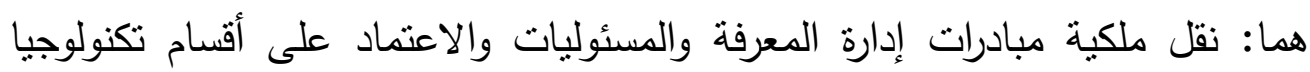
المعلومات لتتفيذ المبادرات، فالافتقار إلى الوعي وعدم كفاية الوقت المخصص

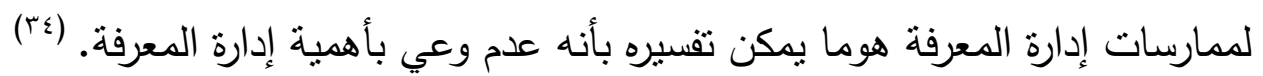

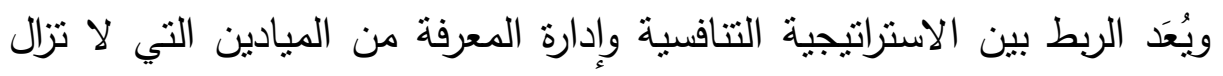
بحاجة إلى تحقيقها ومن ثم ربط الاثثين بالميزة التتافية، وأن تحقيق ذلك لا بد أن يتم

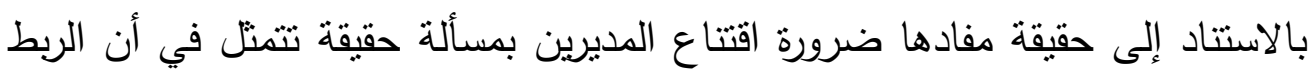

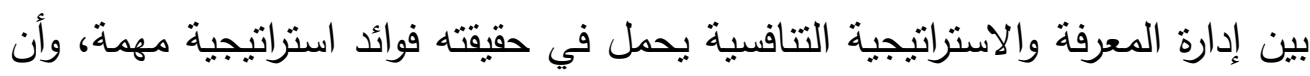

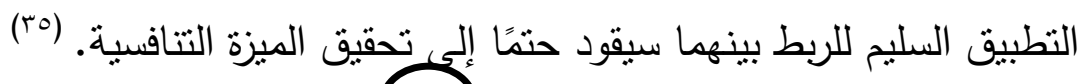




\section{مبررات التصور المقترح:}

تطبيق إدارة المعرفة هي الحل المناسب لكثير من مشكلات المجتمع بمختلف جوانبه، بصفة عامة والمشكلات التربوية والتعليمية في التعليم الثانوي العام بصفة خاصة، لمجموعة من الأسباب: لموابه - الأعداد الكبيرة للملتحقين بالتعليم الثانوي العام، واختلاف مستوياتهم، واحتياجاتهم. - - تتوع الأنشطة الطلابية، وتتعبها. - تعدد الجهات الخدمية، وخدماتها المقدمة للطلاب. - مركزية قواعد البيانات، وصعوبة التعامل معها من خلال الكثيرين. - ازدواجية القرارات التعليمية الخاصة بالتعليم التانوي العام. - تضارب أساليب العمل الإداري بمدارس ومؤسسات التعليم الثانوي العام. متطلبات ومقومات تتفيذ التصور المقترح: يعتمد نجاح التصور المقترح على توفر مجموعة من الإمكانات التتظيمية والمادية والثخصية التي تقود إلى نجاح وتحقيق التصور المقترح لأهدافه، ويُمكن توضيح هذه الإمكانيات بالثكل الآتي: ولئ ولئ

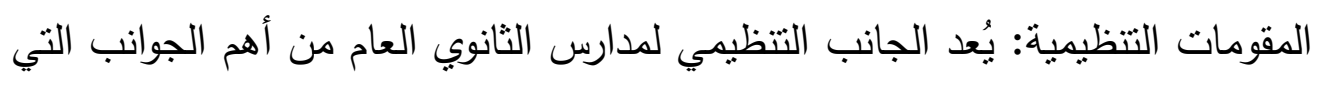
تؤدي إلى تطبيق التصور المقترح بما يحويه من أنماط تتظيمية حديثة ومعاصرة لتهيئة

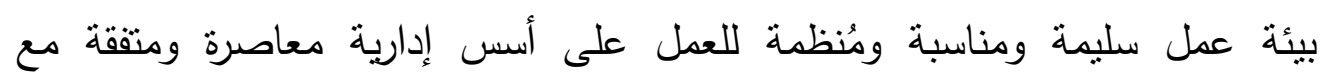
التوجهات العامة للمؤسسة وتعتمد المقومات التتظيمية على مجموعة من المرتكزات المهمة على النحو التالي: - البناء التتظيمي المرتكز على الهيكل التنظيمي الأفقي. - البناء التنظيمي التشاركي في السلطة المبني على الأنظمة واللوائح المحددة لإدارة

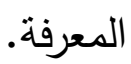
- البناء التتظيمي المبني على اتصالات مفتوحة وخطط علمية واضحة.

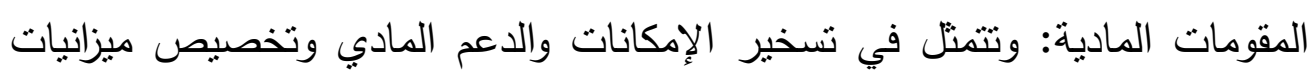

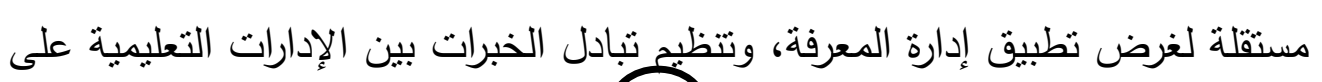


مستوى الجمهورية وكذللك على المستوى العالمي. والتشجيع على نظام اللامركزية. وتتظيم الإنفاق مما يساعد المؤسسة في استثمار الموارد المادية لتنتوع في البرامج والأنشطة التذربيية المقدمة للقيادات والعاملين. المقومات الشخصية: حيث توفير الهيئة الإدارية المُدربة من المتخصصين وأصحاب ولمين الخبرة العالية في مجال البرامج المهنية والاعتماد والجودة وأصحاب التخصص في الإديه التصنيه مجال التتمية المهنية للقيادات التعليمية والعاملين بمدارس الثانوي العام، وعلى أن يتم عملية التقويم بشكل دوري. فعلى مدير إدارة المعرفة (مدير المدرسة) معالجة القضايا الصعبة المرتبطة بالعمليات، تهيئة البنية التحتية الملائمة في مجال التقنيات ويكون الدور تتسيقيًا -لأنها تقع خارج سلطته-، تقييم التكنولوجيا الملائمة والفرص المتاحة، مراقبة الأنشطة الإدارية على كافة المستويات، تطوير رأس المال البشري. والتنفيذ الناجح لتلك لمبادرات تتفيذ إدارة المعرفة يقتضي، وضع الاستراتيجيات، تفعيل السياسات والتشريعات، الدور الفعال للقادة، تتمية رأس المال البشري، إدارة التغيير ، تطوير تكنولوجيا المعلومات، الثراكة والتعاون. عوامل نجاح التصور المفترح: - - توافر قواعد تتظيمية وتكنولوجية. - توفير فرص للمشاركة في الحوار والبحث والروئة المشتركة. - التأكيد على الابتكار ، وتفعيل فرص التعلم المستمر للأفراد. - العمل بروح الفريق، وتفعيل عمل الفرق المختلفة. - - نتني نُظم للتحفيز المادي والمعنوي للعاملين. - - ضمان تعدد القنوات المعرفية لتسهيل عملية نقل المعرفة. - - تبني نقافة (الصداقة المعرفية) التي تساعد على تبادل المعرفة. 


\section{معوقات متوقعة تواجه التصور المقترح وآليات التظلب عليها:}

هناك بعض المعوقات التي من المتوقع بروزها أثناء تتفيذ التصور المقترح، ونظرًا لسرعة التغيرات التكنولوجية التتموية في العصر الحالي فإن نطوير التعليم الثانوي العام من خلال تطبيق إدارة المعرفة يواجه صعوبات في مواكبة تلك التغيرات ولللك فقدرة تللك المؤسسات ومدى تجاوبها مع تللك المتغيرات يؤدي إلى سرعة التغلب

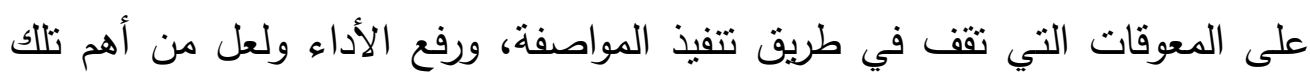
المعوقات ما يلي: - المعات معوقات مالية: يواجه التعليم الثانوي العام ضعف المخصصات والحوافز المالية الكافية للتدريب وتظوير الأداء، وكذلك: معرئ - قلة الإمكانات المادية والتكنولوجية المتاحة للنطبيق. - عدم توافر البنية التحتية للتطبيق. - عدم القدرة على تتفيذ نظام حديث للمعلومات والاتصالات وللتغلب على ذلك يجب: - تفعيل مشاركة المجتمع المدني ورجال الأعمال. - تخصيص ميزانية خاصة من المال العام لتطبيق إدارة المعرفة. معوقات تنظيمبة: - - ضعف الترابط بين التخطيط والتنفيذ والتقييم للعمل الإداري. - الروتين (قاتل الإبداع) والبيروقراطية. - الافتقار إلى القيادة الداعمة لإدارة المعرفة. - سيطرة التقافة التي تكبح وتعيق التشارك في عمليات المعرفة. - - إغفال دور البحث العلمي في حل المشكلات الإدارية. - - نقص واضح في برامج التدريب النوعية الهادفة. - تباين آراء المختصين في تحديد عمليات ومراحل واستراتيجيات إدارة المعرفة. معوقات شخصبة: - عدم رغبة بعض القادة والعاملين في تطبيق إدارة المعرفة. 
- الافتقار إلى الإدراك الكافي لمفهوم وأهمية تطبيق إدارة المعرفة. - عزلة منفذي برامج إدارة المعرفة عن غيرهم من العاملين. ويمكن تقسيم تلاك المعوقات كالتالي:

معوقات ترتبط بتنظيم العمل: حيث توجد مجموعة من المشكلات التي تواجه مدارس الثانوي العام، والتي ترتبط بتتظيم العمل، والهيكل التنظيمي للمدرسة وتتضمن: - تداخل الاختصاصات والعمومية وقلة الوضوح. - تعدد المجالس والمستويات الإدارية في الهيكل التنظيمي. - إغفال الأسس والمبادئ العملية والتتظيمية في مدارس الثانوي العام.

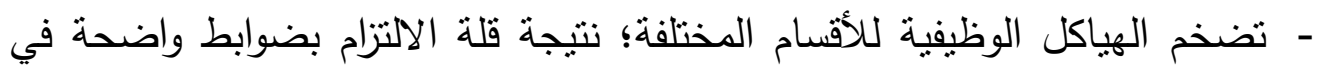
تكوين تلك الهياكل وقلة ربطها بالاحتياجات والأعباء الوظيفية، وشيوع العمالة المقنعة في غالبية الإدارات. - تدني كفاءة بعض العاملين؛ مما يؤدي إلى الصراع والتصادم بين القيادة والمرؤوسين في بعض الأقسام.

- عدم وجود كوادر متخصصة لتطبيق المعرفة. - صعوبة الاتصال بين المستويات الإدارية الوسطى والتتفيذية وبين بعضها البعض من ناحية وبينها وبين المستويات الإدارية العليا من ناحية أخري. - - الروتين والتعقيد الوظيفي والإداري. - التزميم التنظيمي وعدم إصلاح الإدارات التعليمية المتعثرة. - عدم تشجيع الرؤساء على ممارسة القيادة وليس الرئاسة. - المركزية الثديد في اتخاذ القرارات. - - تعدد الأهداف وتعارض الأولويات. - عدم استثمار الموارد البشرية بالإدارات لإعادة تشكيل القدرات التتافسية واستثمارها. - - عدم الاتجاه إلى التعامل بمنطق العولمة. - القصور في البرامج التدريبة التي تهدف لتطبيق إدارة المعرفة. 


\section{معوقات ترتبط بالعاملين:}

- - عدم رغبة البعض في التعاون والمشاركة.

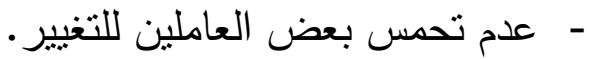

- ت تدني معرفة كثير من العاملين والقيادات الإدارية بأهمية تطبيق إدارة المعرفة. - انتشار الصراعات والغيرة بين العاملين. سبل التغلب على هذه المعوقات:

- العمل على إقناع جميع المستويات الإدارية بالتعاون من أجل تطبيق إدارة المعرفة.

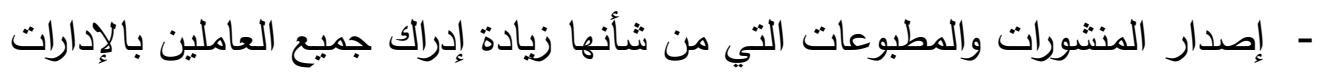
بأهمية تطبيق إدارة المعرفة لتحقيق الميزة التنافسية.

$$
\text { - - البحث عن موارد جديدة بديلة. }
$$

- إعداد دراسات وخطط وبرامج وموازنات تحقيق التعاون والتتسيق فيما بين الإدارات.

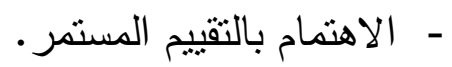
محتوى التصور المقترح لتحقيق الميزة التتافسية للتعليم الثانوي العام بمصر في ضوء إدارة المعرفة، وآليات تتفيذه: تطبق إدارة المعرفة من خلال تفعيل الأساليب التالية:

\section{أساليب اكتساب المعرفة:}

- التوسع في استخدام تكنولوجيا المعلومات الحديثة - استخدام نُظم الاتصالات الحديثة (واي فاي، هواتف محمولة،.....) - توفير مكتبة رقمية للحفاظ على المعلومات والمعارف التي تساعد على اكتساب المعرفة.

- توفير بوابة إلكترونية للمدرسة (فيس بوك، تويتر) لسهولة تدفق المعلومات. - توافر وسائل تعلم دائمة ومتطورة داخل المدرسة (السبورة الذكية، البروجكتور ،....) - الحرص على نقل المعرفة العلمية أثناء برامج تدريبية حديثة. 
- اكتشاف المبدعين من القائمين على العملية التعليمية للاستفادة من خبراتهم.

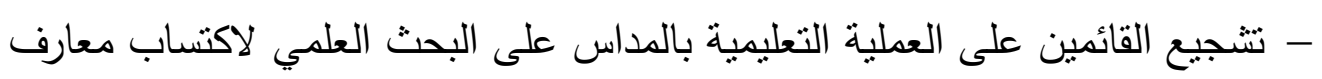
جديدة.

- إعداد برامج علاجية وتدريبية الأقل خبرة ومهارة من القائمين على العملية التعليمية. - العمل على تتجيع العمل التعاوني بين القائمين على العملية التعليمية (ورش عمل

$$
\text { وندوات،...... }
$$

- الحرص على نشر ثقافة المعرفة، بما تتفق مع متطلبات مجتمع المعرفة.

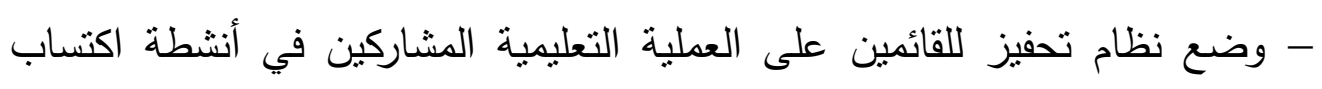
المعرفة.

- التأكد من إتقان العاملين لاستخدام استراتيجيات جديدة لاكتساب المعرفة. أساليب توليد المعرفة: - - استقطاب الكوادر البشرية المدربة وذات الخبرة للعمل بالمدرسة. - تشجيع العاملين بالمدرسة على التتافس الثريف فيما بينهم. - تقعيل فرق عمل لحل المشكلات وقت حدوثها. - - تفعيل التدربيات للعاملين بالمدرسة. - ـ وضع نظام للتحفيز المادي والمعنوي. - - تشجيع الحوار العلمي البناء بين العاملين.

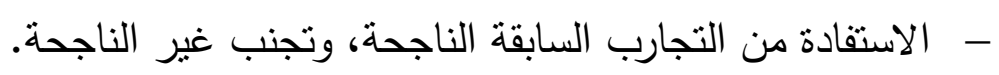
أساليب تخزين واسترجاع المعرفة: - استخدام نظم حديثة في تخزين المعرفة (قواعد بيانات، مكتبة رقمية). - استخدام نظام فعال لتأمين وحماية المعرفة المخزنة (تشفير البيانات). - تحويل الأصول المعرفية مثل: مراجع المدرسة إلى صورة الكترونية يسهل تخزينها. - استخدام نظم سريعة لاسترجاع المعرفة المخزنة.

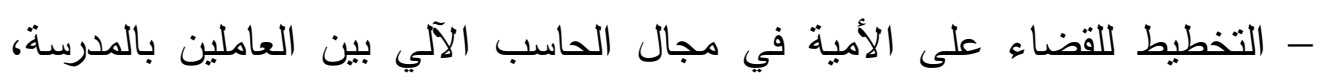
للتعامل مع مصادر المعرفة. 
- تحويل المستتدات الورقية إلى إلكترونية. - إنشاء وحدة لإدارة المعرفة بالمدرسة، هدفها تخزين واسترجاع المعرفة. - تقييم مستمر للمعرفة المخزنة؛ لضمان سلامة توظيفها.

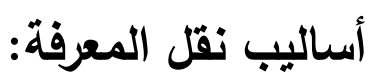
- التعاون مع خبراء من خارج المدرسة للمشاركة في الندوات والمحاضرات وورش العمل بالمدرسة.

- تعزيز مناخ داعم لتبادل المعارف المختلفة بداخل المدرسة. - - توظيف وسائل الإعلام ومواقع التواصل الاجتماعي؛ لنقل المعرفة.. - مساعدة العاملين بالمدرسة للاستفادة من قواعد المعرفة. - تفعيل اللقاءات الدورية بين العاملين المدرسة. - - تصميم برامج تدريبية هدفها اكتساب مهارة نقل المعرفة. - تشجيع العاملين على تبادل المعرفة. أساليب تطبيق المعرفة:

- تحليل المعرفة المتوفرة قبل البدء في تطبيقها. - توفير متطلبات تطبيق المعرفة المادية والبشرية. - - استخدام المدرسة مقاييس ومعايير محددة للسيطرة على المعرفة المطبقة. - الاستفادة من التجارب الناجحة في تطبيق إدارة المعرفة. - - وضع استراتيجيات فعالة لنطبيق إدارة المعرفة. - - نطوير آليات استخدام الرصيد المعرفي بالمدرسة بفاعلية. - - الاستعانة بالخبراء والهيئات الاسنتارية لدعم خطط تطبيق إدارة المعرفة. - - تحليل مدى كفاءة تطبيق المعرفة المتوفرة. - تشكيل فرق عمل لتطبيق إدارة المعرفة. - - تشكيل فرق عمل لمتابعة وتقييم تطبيق إدارة المعرفة. 
مقترحات تساعد على تطبيق التصور المقترح: - - توفير الإمكانات المادية والبشرية والمعنوية. - - تحفيز العاملين بالدرسة، وتثجيعهم. - تطوير نظم تدريب العاملين، ونقل الخبرات. - تفعيل ورش العمل، وتطوير فرق العمل المختلفة.

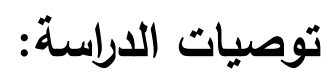
توصلت الدراسة إلى مجموعة من التوصيات، أهمها:

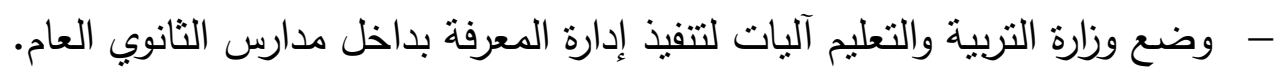
- علاج وزارة التربية والتعليم لمشكلات المعلم المادية والمعنوية.

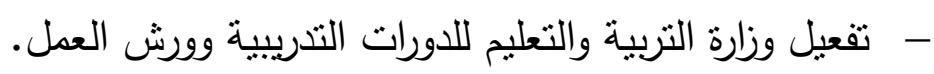

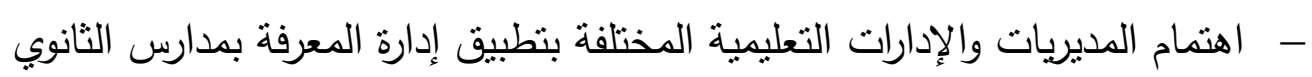
العام.

- - استخدام المدرسة لنظم المعلومات والاتصالات الحديثة. - تثجيع العاملين بمدارس الثانوي العام على البحث العلمي، والتتافسية فيما بينهم. 


\section{قائمة المراجع}

(1) محمود مصطفي هلال: منطلبات تطوير الإدارة الجامعية في ضوء بعض الخبرات العالمية (دراسة حالة جامعة المنصورة)، رسالة دكتوراه غير منشورة، كلية التربية،

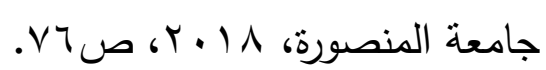

(r) إيمان جميل عبد الرحمن، إبراهيم حربي تادرس: "مستوى ممارسة إدارة المعرفة في جامعة البلقاء التطبيقية من وجهة نظر الإداريين العاملين في الإدارة الوسطي والعليا"، مجلة العلوم التربوية والنفسية، مجلد 10 ، مركز النشر العلمي، جامعة الطداء

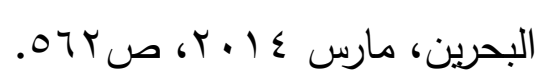

(r) طاهر محمد الهادي: "المنهج المتمايز في الألفية الثالثة بين رأس المال الفكري

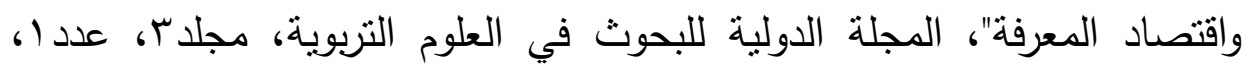

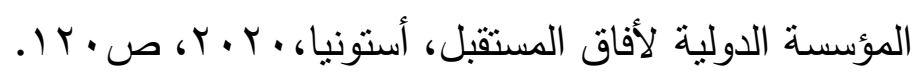

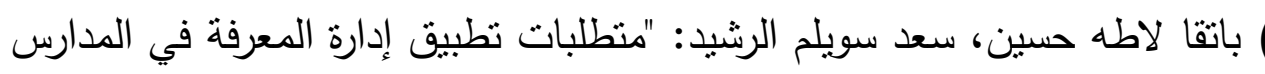
الثانوية من وجهة نظر القادة التربويين بمدينة تبوك"، مجلة جيل العلوم الإنسانية

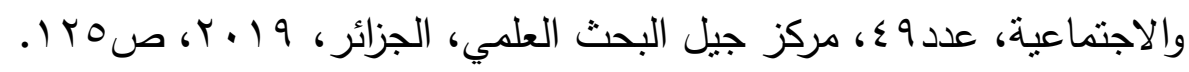

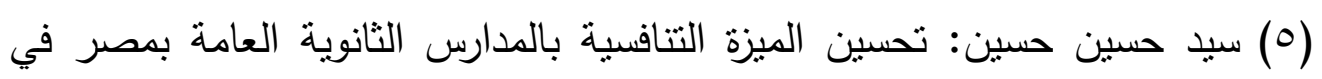
ضوء مدخل إدارة رأس المال الفكري، رسالة ماجستير غير منشورة، كلية التربية،

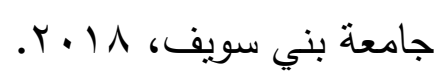

عدنان محمد قطيط: "تحسين مؤشرات التتافسية للتعليم قبل الجامعي في مصر سيناريوهات بديلة"، المؤتمر الدولي لمعهد التخطيط القومي، بعنوان: نحو تعليم

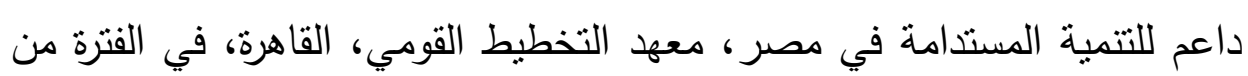

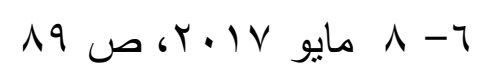

صالح عبد الحكيم عبد الغفور : متطلبات إدارة المعرفة ودورها في تحقيق الميزة التنافسية في جامعات غزة، رسالة ماجستير غير منشورة، أكاديمية الإدارة

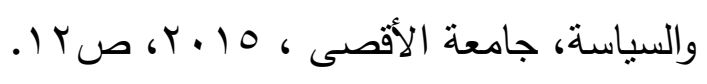


(^) مديحة فخري محمد: "تصور مقترح لترسيخ أخلاقيات الأعمال لرفع القدرة التتافسية

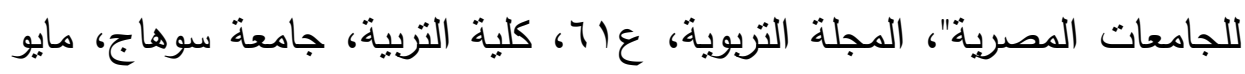

$$
.09 \cdot 06 r \cdot 19
$$

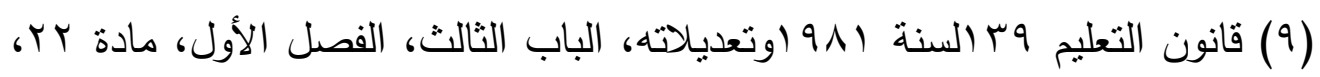

$$
\text { صنr }
$$

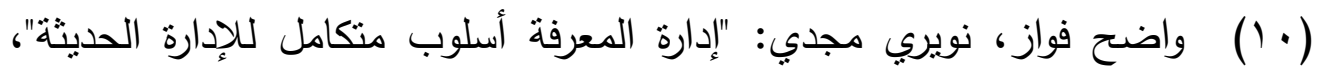

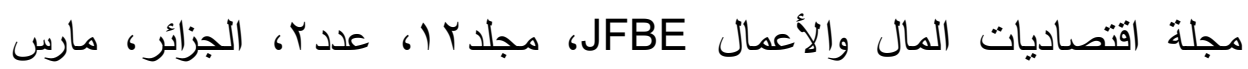

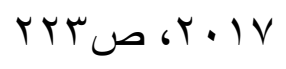

(1) (1) مها علي السيد محمد: تصور مقترح لتكامل مدخل إدارة المعرفة ومجال الفاعلية التعليمية لتحقيق الجودة بالمدارس الثانوية العامة" بمحافظة الدقهلية،

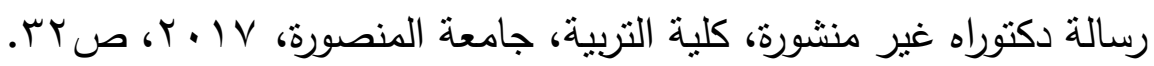
(Y ( ) هيئة الإمارات للهوية: المنظمة العربية للتتمية الإدارية، جامعة الدول العربية:

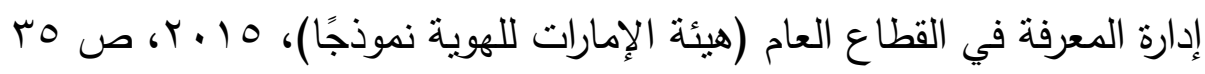
Available online at: https://www.slideshare.net/alkhouri/ss46529229

(r (1) ريما علي حلاق: دور إدارة المعرفة في اتخاذ القرارات من وجهة نظر المديرين والمدرسين في المدارس الثانوية العامة في مدينة دمشق، رسالة ماجستير غير

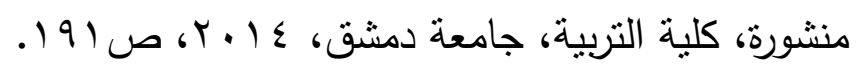

(ع () نورا حسن المتولي العايق: دور الجهاز الإداري في تحقيق رسالة جامعة المنصورة باستخدام مدخل إدارة المعرفة، رسالة ماجستير غير منشورة، كلية

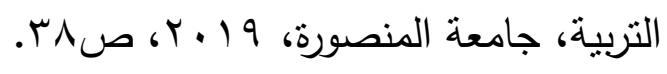

(15) V. Maria Tresita Paul, author G. Prithiviraj: Knowledge Management Key to Competitive Advantage, Emerging Trends in Science, Engineering and Technology, December 2012, P. 778. 
Available online at:

https://link.springer.com/chapter/10.1007/978-81-322-1007-

\section{8_74}

(7 (1) نبوية عيسي، عواطف خلوط: "توظيف إدارة المعرفة في مؤسسات التعليم العالي - دراسة حالة كلية العلوم الاقتصادية والتسبير بجامعة تلمسان"، مجلة العلوم

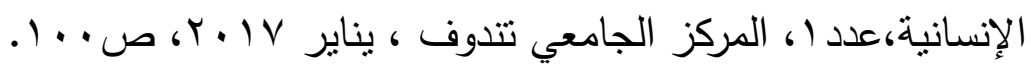
(lV) خالد عتيق عبد الله، جاسم محمد جرجيس: "إدارة المعرفة- مفهومها، وأهميتها، وواقع تطبيقها في المكتبات العامة في دولة الإمارات العربية المتحدة من وجهة نظر مديريها"، مجلة مكتبة الملك فهد الوطنية، مجلد آب، عدد Y، مجلس الوزراء،

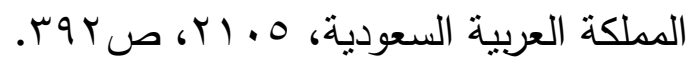
(1) باسم غدير غدير: "متطلبات ومعوقات تطبيق إدارة المعرفة (جامعة تشرين نموذجًا)"، مجلة جامعة تشرين للبحوث والدراسات العلمية، سلسلة العلوم

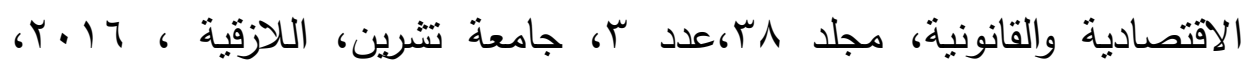
ص99

(9 1) فيصل غازي المطيري: أثز التوجه الإبداعي على تحقيق ميزة تتافسية- دراسة تطبيقية على البنوك التجارية الكويتية، رسالة ماجستير غير منشورة، كلية التجارة،

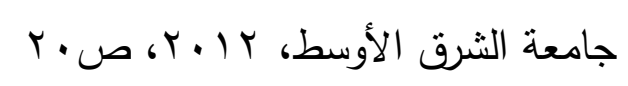

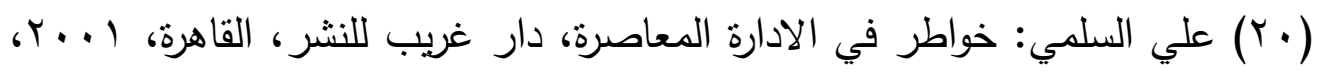

ص ص

(Y) مصطفى محمود أبو بكر : الموارد البشرية-مدخل لتحقيق الميزة التتافسية، الدار

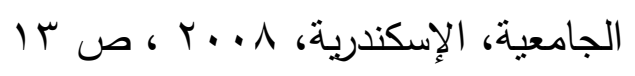

(Y ) آمال سيد مسعود: "ملامح استراتيجية لتحقيق الميزة التتافسية للمدارس الحكومية الإسية بالتعليم العام في مصر"، مجلة كلية التربية، مجلد ب، عدد وهـ، كلية التربية،

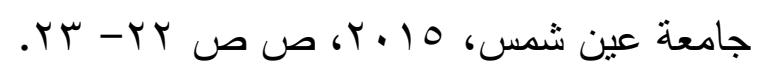


(23) Wang Wen-Cheng et. all: Types of Competitive Advantage and Analysis, International Journal of Business and Management, Vol. 6, No. 5; May 2011,P.P101-102

Available online at:

http://www.ccsenet.org/journal/index.php/ijbm/article/view/10 432

(Y (Y) عبير فاروق أكبر : "ممارسات القيادات الإدارية لتحقيق الميزة التتافسية بمدارس التعليم الثانوي في محافظة جدة بالمملكة العربية السعودية"، مجلة البحث العلمي في التربية، عدد 11، كلية البنات للآداب والعلوم والتربية، جامعة عين شمس، باله

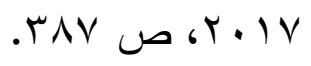

(Yo) أماني عبد العظيم شلبي: متطلبات تحقيق الميزة التنافسية لجامعة المنصورة في ضوء بعض الخبرات العالمية- رؤية تربوية معاصرة، رسالة دكتوراه غير منشورة،

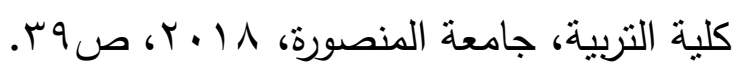
(Y7) محمود فوزي بدوي، عماد نجم مصطفي: "تعزيز تتافسية التعليم العالي المصري مدخلًا لتطوير واقع مؤسساته في تصنيفات نخبة الجامعات العالمية"، المجلة

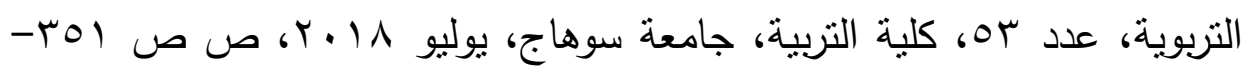
TOY عبد الناصر عطايا، عصام رمضان: "مستوى الصحة المنظمية بالمدارس (YV) الثانوية من وجهة نظر معلمي التعليم الثانوي العام بمصر"، مجلة جامعة النجاح

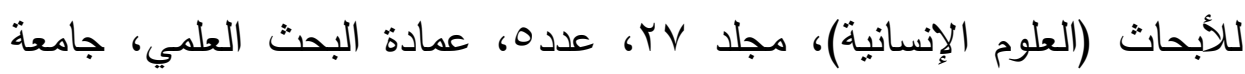

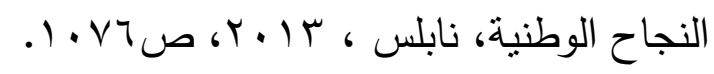
(Y^) السياسات التعليمية في مصر: مركز هردو لدعم التعبير الرقمي، القاهرة، .$r \cdot 11$

Available online at: https://hrdoegypt.org/wpcontent/uploads/2018/ 
(Yq) برنامج الأمم المتحدة الإنمائي ومؤسسة محمد بن راثد آل مكتوم: مؤشر المعرفة

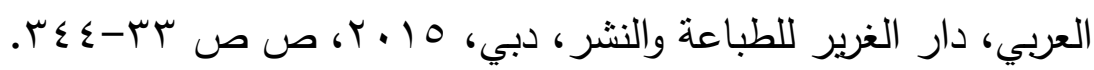

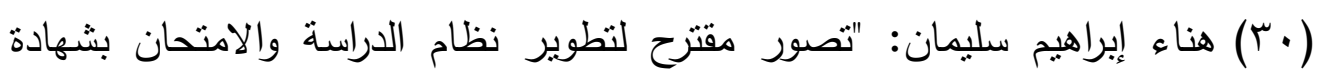
الثانوية العامة في مصر على ضوء سياسات القبول بالتعليم العالي"، مجلة

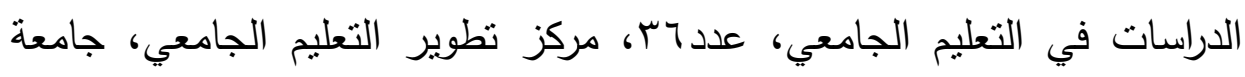

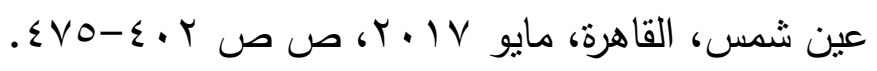

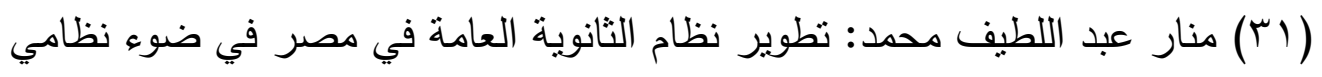
الدبلومة الأمريكية والثانوية الإنجليزية، رسالة دكتوراه غير منشورة، كلية التربية،

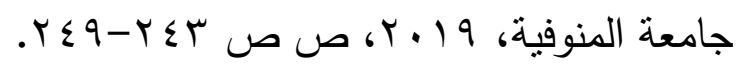

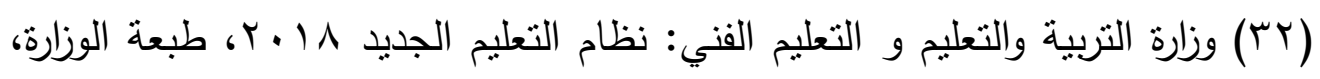

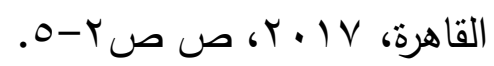
(rT) عبد الحميذ مظهر : نحو رؤية مستقبلية للتعليم للمئة سنة القادمة- أفكار غير

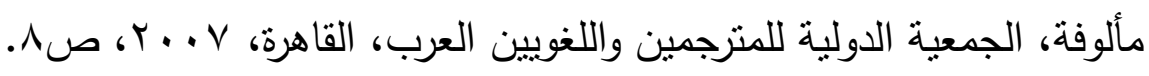
Available online at:

http://www.wata.cc/forums/showthread.php?21026 (؟) علي محمد الخوري: إدارة المعرفة في القطاع العام- استعراض تجربة ناجحة

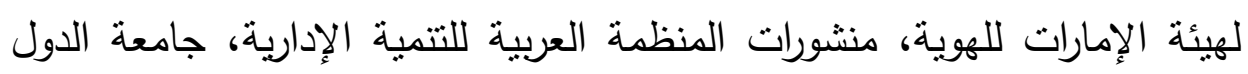

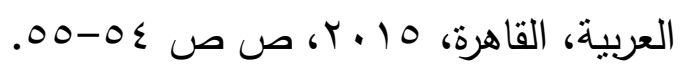

(مب) راتب صويص، وآخرون: "عمليات إدارة المعرفة وتأثيرها في تحقيق الميزة التتافسية- دراسة حالة لمجموعة الاتصالات الأردنية (Orange)"، المجلة

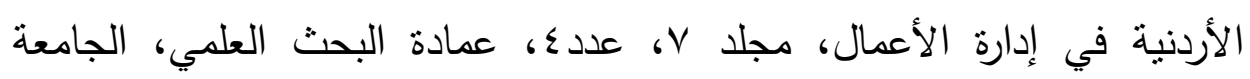

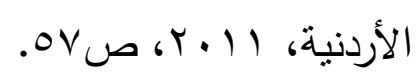

